\title{
Proper Choice of Urban Canopy Model for Climate Simulations
}

\author{
Zahra Jandaghian ${ }^{1}$, Umberto Berardi ${ }^{2}$ \\ ${ }^{1,2}$ Ryerson University, Toronto, Canada
}

\begin{abstract}
The Weather Research and Forecasting model (WRF) is coupled with the three types of Urban Canopy Models (UCMs) to predict heat and moisture fluxes from the canopy to the atmosphere. The three UCMs are slab, single-layer, and multi-layer. The WRF-UCMs are applied to investigate the impacts of summer heat on urban climate and characterize the heat island intensity in the Greater Toronto Area (GTA) during the 2011 heat wave period $\left(17^{\text {th }}-21^{\text {st }}\right.$ July $)$. The WRF-UCMs are evaluated using simulated hourly air temperature and wind speed results with measurements obtained from various weather stations across the domain of interest. The multi-layer of the urban canopy model (ML-UCM) predicts air temperature and wind speed more accurately comparing to other UCMs. The ML-UCM accounts for the turbulence and multi-reflection within the urban canopy and increases the computation time $30-40 \%$ compared to other canopy models (single and slab model).
\end{abstract}

\section{Introduction}

Changing land surface properties from permeable and moist areas (e.g. vegetated lands) to dry and impermeable (e.g. roads and buildings) reduces evaporation and latent heat fluxes (Wong, 2008). Roofs and pavements cover $60 \%$ of urban areas that absorb more than $80 \%$ of the incoming solar radiation, whereas human activities enhance heat generation simultaneously (Akbari et al., 2003; 2008; 2009; Wang et al., 2015; Jandaghian and Akbari, 2016; 2017). Hence, urban areas are typically warmer than their surroundings because of the urban heat island (UHI) phenomenon (Jandaghian and Akbari, 2017). Studies show a worldwide spread of the UHI effect (Berardi et al., 2014; Berardi 2016; Wang et al., 2016; Jandaghian et al., 2017; Jandaghian and Akbari 2018a, 2018b; 2018c).

In urban areas, meteorological variables are influenced by physical processes in the atmosphere and on the ground. Mesoscale models are applied for urban climate simulations to consider the impacts of altering the land use/land cover. Mesoscale models can be coupled with the urban canopy models (UCM) to calculate the heat and moisture fluxes from the surfaces to the atmosphere (Jandaghian 2018; Jandaghian et al., 2018). Urban Canopy Models (UCMs) can provide more accurate feedback of urban areas for surface and planetary boundary layer models. Adding different forms of heat flux to the urban canopy model and increasing the level of complexity has a significant effect on predicting the UHI intensity (Grimmond et al., 2010).

To calculate the heat and moisture fluxes from the surfaces to the atmosphere, mesoscale models are applied for urban climate simulation and coupled with the urban canopy models (Jandaghian et al., 2017). The Weather Research and Forecasting model (WRF is an online numerical mesoscale meteorological model that incorporates three types of Urban Canopy Models; slab (bulk), single layer, and multi-layer. The appropriate UCM to use depends on the compatibility of the mesoscale model, computational time cost and resources, and the level of detailed information required for analysis. The proper choice of the UCM is required to understand the effects of surface modification strategies on urban climate. The focus of this study is to assess the performance of the different urban canopy models of the WRF in characterizing the urban heat island during the 2011 heat wave period in the Greater Toronto Area (GTA). The GTA is the most populated area in Canada with more than 6 million inhabitants (Statistics Canada, 2016). While being in a cold climate zone, the heatwaves have significant impacts on vulnerable people especially infants and elderly (Yardley et al., 2011; Oliver et al., 2015). The WRF and the three types of UCMs are explained in the methodology section. The results and analyses include the model performance evaluation and the estimation of $2-\mathrm{m}$ air temperature and $10-\mathrm{m}$ wind speed during the heat wave period in the GTA. The conclusion presents the limitations and assumptions of these simulations with the future steps.

\section{Urban canopy models (UCMs)}

Built-up structures affect the momentum, turbulence and thermal exchanges between the surface and the atmosphere. Thus, the Urban Canopy Models (UCMs) are applied to indicate more accurate feedback of urban areas regarding to land surface parameterizations and planetary boundary layer (Jandaghian and Berardi, 2019a and 2019b). WRF incorporates three types of UCMs; slab (bulk), single layer, and multi-layer. Slab models are a one-dimensional UCMs that consider buildings as an increased roughness in urban areas and indicates zeroorder effects of urban surfaces (Liu et al., 2006). Singlelayer UCM provides an accurate estimation for sensible heat fluxes and calculates the radiation trapping effects because of the multi-reflections in urban geometry 
(Kusaka et al., 2001). SL-UCM considers twodimensional approximation for streets with a single orientation. The Multi-layer of the UCM calculates the impacts of a complex urban surface within their vertical mixing. Martilli et al., (2002) developed the ML-UCM and Chen et al., (2011) integrated the model in mesoscale models (Jandaghian and Akbari, 2019).

\section{Methodology and simulation setup}

Toronto is centred at the $\sim 43.7^{\circ} \mathrm{N}$ and $\sim 79.3^{\circ} \mathrm{W}$. The horizontal domain of the simulations is composed of four two-way nested domains. Figure 1 shows the Google map and the fourth simulation domain covering the GTA. The 51eta vertical level is telescopically defined to take full advantages of the urban parameterization. The simulation is conducted during the 2011 heat wave period in GTA, started from the $17^{\text {th }}$ of July and lasted for five consecutive days. The first $24 \mathrm{hrs}$ of the simulation results are disregarded as a spin-up time.

The initial and boundary conditions were obtained from the North American Regional Reanalysis (NARR) (Mesinger et al., 2006). The land-surface model NOAHLSM provides skin temperature, surface sensible and latent heat fluxes as lower boundary conditions for the meteorological model. The Mellor-Yamada-Janjic scheme (Janjic, 1994, 2002) used Eta similarity theory (Janjic, 2002) to estimate the planetary boundary layer. The Rapid Radiative Transfer Model (RRTMG; Iacono et al., 2008) is applied to estimate the impacts of shortwave and longwave radiations. We employed the Lin scheme (Lin et al., 1983 \& 2011) and Grell 3D (Grell and Devenyi, 2002) schemes for microphysics and cumulus models, respectively (Jandaghian et al., 2017).

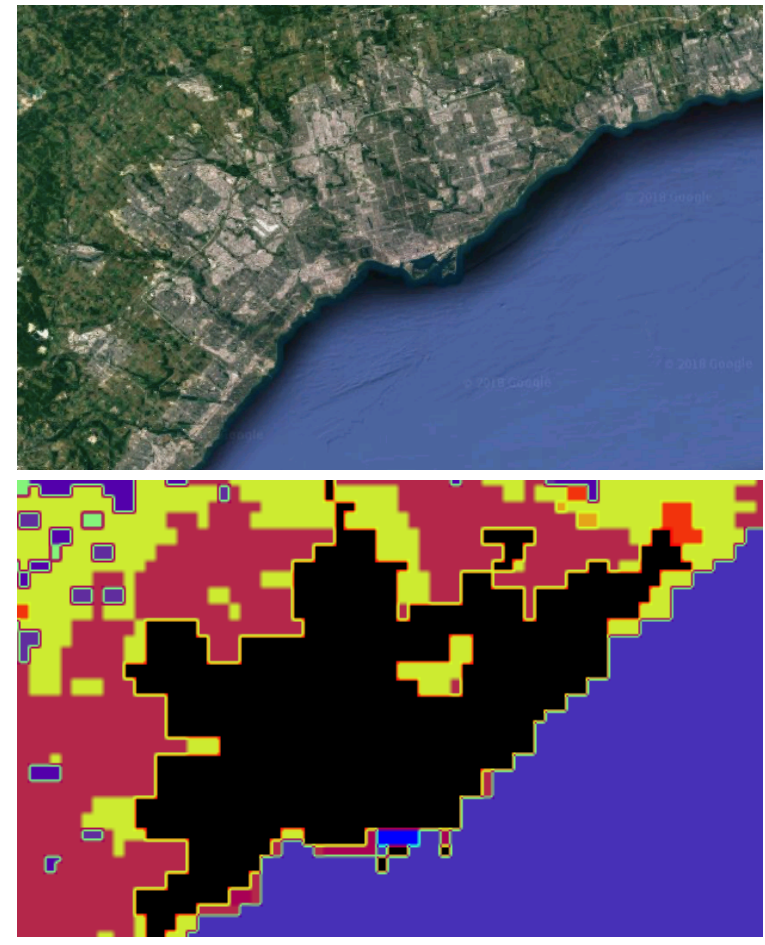

Figure 1: The Greater Toronto Area on Google map (above) and the 4th domain of simulation with LULC (below)

(black regions show the urban area)

\section{Results and analysis}

We compare the WRF-UCMs' meteorological parameters of 2-m air temperature (T2) and 10-m wind speed (WS10) predictions to measurements obtained from urban and rural weather stations across the GTA. Here, the hourly results of the July 20th are evaluated. Three weather stations are selected: City Centre (CC-in the downtown of the GTA); Pearson Airport (PA), and Bottonville (BOrural area). Figure 2 shows the location of these weather stations in GTA. The measured data are from Climate Canada Historical Data (http://climate.weather.gc.ca/).

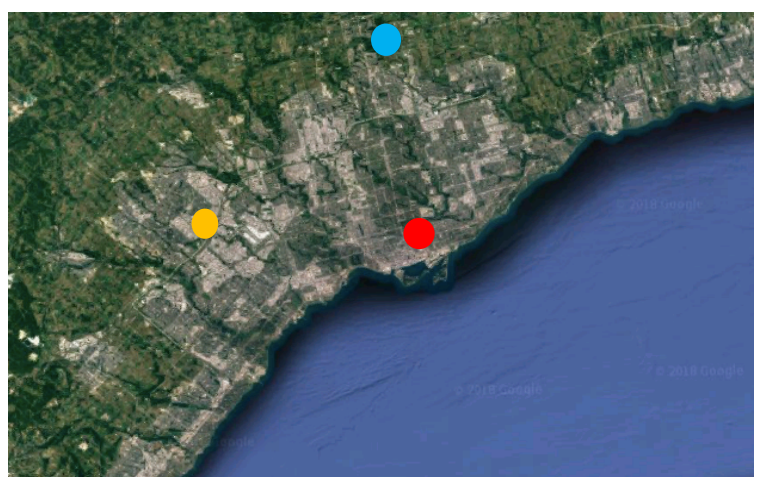

Figure 2: The geographical location of weather stations in $G T A$, the red, yellow and blue circles respectively represents City Centre (CC), Pearson Airport (PA) and Bottonville (BO)

For statistical analysis of the UCMs, the Mean Bias Error (MBE, Equation (1)); Mean Absolute Error (MAE, Equation (2)) and Root Mean Square Error (RMSE, Equation (3)) are calculated to evaluate the model performances (Jandaghian and Akbari 2018a, 2018b).

$$
\begin{gathered}
M B E=\frac{\sum_{i=1}^{24}\left(\mathrm{C}_{S}-\mathrm{C}_{M}\right)}{24} \\
M A E=\frac{\sum_{i=1}^{24}\left|\mathrm{C}_{S}-\mathrm{C}_{M}\right|}{24} \\
R M S E=\left[\frac{\sum_{i=1}^{24}\left(\mathrm{C}_{\mathrm{S}}-\mathrm{C}_{\mathrm{M}}\right)^{2}}{24}\right]^{0.5}
\end{gathered}
$$

Where $\mathrm{C}_{\mathrm{S}}$ and $\mathrm{C}_{\mathrm{M}}$ are the simulated and measured parameters, respectively.

\section{Air temperature}

Table 1 presents the statistical analyses of 2-m air temperature in three weather stations across the GTA using the Slab (SB), single-layer (SL) and multi-layer (ML) of the UCMs. The RMSE of the ML-UCM $\left(1.4^{\circ} \mathrm{C}\right)$ is lower than other UCMs across the entire domain. But the comparisons among urban canopies indicated that in the downtown of Toronto, the prediction of 2-m air temperature is similar in single and multi-layer of the UCM. In the urban area SL-UCM estimates the air temperature more accurately with a MAE of about $1^{\circ} \mathrm{C}$. The UCMs show a tendency to underestimate the air temperature in the simulation domain. 
Table 1: The Mean Bias Error (MBE), Mean Absolute Error (MAE), and Root Mean Square Error (RMSE) of 2-m air temperature in GTA during the 2011 heatwave. SB (Slab); SL (Single-layer); ML (Multi-layer); Sta. (Station); CC (City Centre); PA (Pearson Airport); BO (Bottonville)

\begin{tabular}{llllllllll}
\hline Sta. & \multicolumn{3}{c}{ MBE $\left({ }^{\circ} \mathbf{C}\right)$} & \multicolumn{4}{c}{ MAE $\left({ }^{\circ} \mathbf{C}\right)$} & \multicolumn{3}{c}{ RMSE $\left({ }^{\circ} \mathbf{C}\right)$} \\
\cline { 2 - 10 } & SB & SL & ML & SB & SL & ML & SB & SL & ML \\
\cline { 2 - 9 } CC & -0.7 & -0.6 & -0.7 & 1.1 & 1.0 & 0.9 & 1.4 & 1.3 & 1.1 \\
\cline { 2 - 10 } PA & -1.6 & -1.6 & -1.5 & 2.6 & 2.6 & 1.5 & 3.2 & 3.1 & 2.0 \\
\cline { 2 - 10 } BO & -0.2 & -0.5 & -0.5 & 1.0 & 0.9 & 1.4 & 1.3 & 1.1 & 1.0 \\
\cline { 2 - 10 } Avg. & -0.8 & -0.9 & -0.9 & 1.5 & 1.5 & 1.2 & 2 & 1.7 & 1.4
\end{tabular}

Figure 3 shows the hourly 2-m air temperature variation in the weather station (City Centre) located in the urban area and the simulations using three UCMs on the $20^{\text {th }}$ of July 2011 .
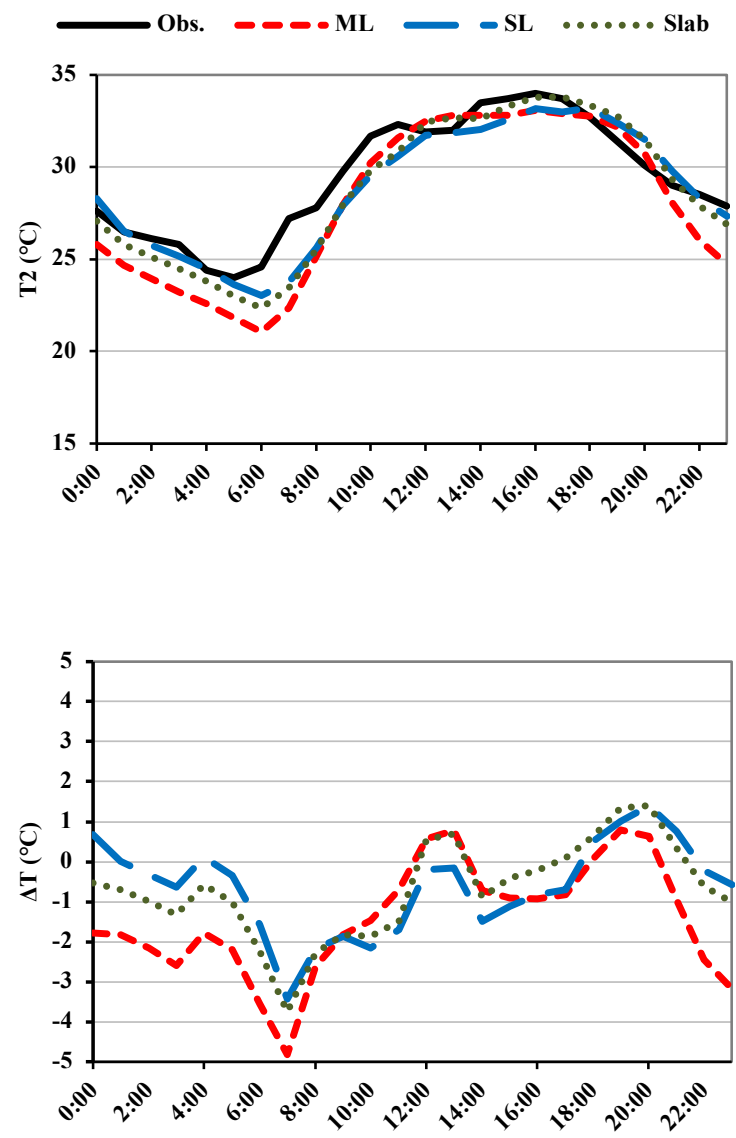

Figure 3: Hourly simulated and observed 2-m air temperature [top] and the difference between simulated and measured temperature [bottom] in the urban areas of GTA on $20^{\text {th }}$ July 2011 using the WRF coupled with the three UCMs.

In Toronto, except for a few hours in the evening, the UCMs have a tendency to underestimates the air temperature. There are two peaks between the difference of simulated and measured air temperature using ML$\mathrm{UCM}$ in early morning and late night $5^{\circ} \mathrm{C}$ and $3^{\circ} \mathrm{C}$. The large differences occurred where the measured temperature has a sharp change. The 2-m temperature of SL-UCM and slab model almost has the same pattern. The anthropogenic heat emission added to the SL-UCM resulted in a better estimation of the 2-m air temperature. However, as discussed in previous research (Salamanca et al., 2011; 2012), compiling these models with other building energy simulation tools will potentially reveal more details regarding to the effects of heat island intensity in urban areas.

\section{Wind speed}

The three UCMs underestimate the 10-m wind speed in the Greater Toronto area (Table 2). In the urban area, the ML-UCM underestimates and other UCMs overestimate the wind speed. ML-UCM has the largest MAE and RMSE in the domain and the smallest MAE and RMSE in the urban area, respectively. The average MAE and RMSE of UCMs in the domain are almost the same but these criteria are significantly improved in urban areas by using ML-UCM. Table 3 shows the result of simulations where the three UCMs overestimate the wind speed. MLUCM improved the accuracy of the model by reducing the MAE and RMSE of the summer day.

Table 2: The Mean Bias Error (MBE), Mean Absolute Error (MAE), and Root Mean Square Error (RMSE) of 10-m wind speed air temperature in GTA during the 2011 heatwave. SB (Slab); SL (Single-layer); ML (Multi-layer); Sta. (Station); CC (City Centre); PA (Pearson Airport); BO (Bottonville)

\begin{tabular}{llllllllll}
\hline Sta. & \multicolumn{3}{c}{ MBE $\left({ }^{\circ} \mathbf{C}\right)$} & \multicolumn{3}{c}{ MAE $\left({ }^{\circ} \mathbf{C}\right)$} & \multicolumn{3}{c}{ RMSE $\left({ }^{\circ} \mathbf{C}\right)$} \\
\cline { 2 - 10 } & SB & SL & ML & SB & SL & ML & SB & SL & ML \\
\hline CC & 3.0 & 2.4 & -1.6 & 4.4 & 3.9 & 3.2 & 5.3 & 4.8 & 3.7 \\
\hline PA & 4.0 & 4.2 & 3.8 & 4.4 & 4.7 & 4.7 & 5.2 & 5.5 & 5.6 \\
\hline BO & 4.8 & 4.5 & -1.0 & 5.8 & 5.6 & 3.0 & 7.3 & 6.7 & 3.5 \\
\hline Avg. & 3.9 & 3.7 & 0.4 & 4.9 & 4.7 & 3.6 & 5.9 & 5.6 & 4.2 \\
\hline
\end{tabular}

\section{Urban heat island intensity}

Figure 4 illustrates the 2-m air temperature in the urban and rural areas of the GTA during the simulation period. The observation shows that the nocturnal UHI is intensive, starting in the evening. The ML-UCM gives a more accurate prediction of UHI, while, other UCMs overestimating it during the night-time. The UHI intensity of Toronto is well predicted by the ML-UCM without considering the anthropogenic heat emission. Adding heat emission from buildings increases the air temperature of the urban areas mainly during the night (anthropogenic heat emission is much smaller than the solar radiation during the day) that would result in a better estimation of nocturnal UHI intensity (Salamanca et al., 2011). 


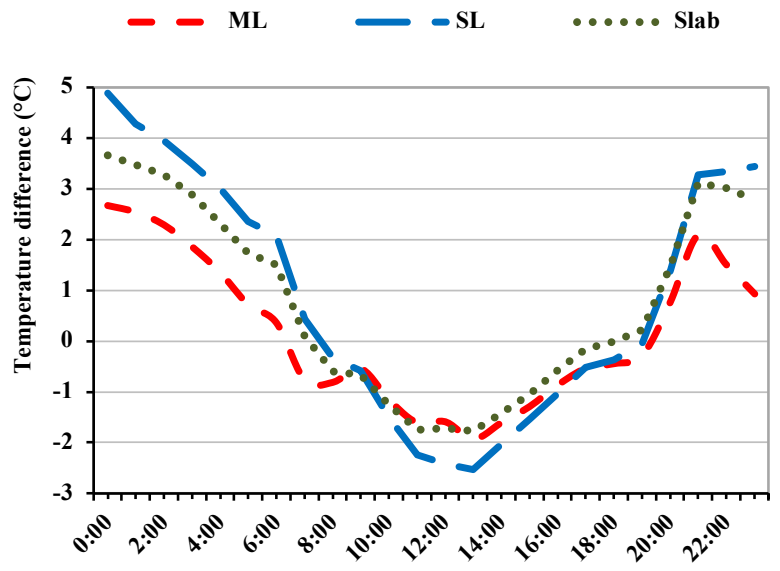

Figure 4: Temporal variation of 2-m air temperature $\left({ }^{\circ} \mathrm{C}\right)$ difference between urban and rural area of the GTA in 20th of July 2011 using three UCMs: Slab, Single and Multi-layer.

Historically, atmospheric UHI intensity is defined as the difference between the air temperature of urban areas and their surroundings. In some researches, an index based on the skin surface temperature is considered as the indicator of UHI intensity (Jin, 2012; Gupta, 2012). The Ontario Lake has a significant effect on regulating the temperature of Toronto, especially during the daytime. Near the water body, even in the daytime, the temperature is lower than the other regions. The atmospheric UHI is magnified during night. Skin temperature is well represented the urban boundaries. It can be concluded that skin temperature is mostly related to the urban fabric and is again lower near the lake.

\section{Conclusions}

We compared the three Urban Canopy Model in the Weather Research and Forecasting model (WRF-UCM) for urban climate simulations in the Greater Toronto Area during the 2011 heat wave period. The three UCMs (i.e. multi-layer, single-layer, and slab model) have the tendency to underestimate the 2-m air temperature and overestimate the $10-\mathrm{m}$ wind speed across the domain. The correlation between air temperature of different UCMs and measured data is close to 1 , whereas the correlation between wind speed simulations and measurement was poor.

The averaged of mean absolute error of 2-m air temperature and $10-\mathrm{m}$ wind speed were about $1.4^{\circ} \mathrm{C}$ and $4.4 \mathrm{~m} / \mathrm{s}$, respectively. Similarly, the root mean square error of temperature and wind speed were $1.7^{\circ} \mathrm{C}$ and $5.2 \mathrm{~m} / \mathrm{s}$. Urban heat island intensity is well characterized by the multi-layer of the UCM. Our analysis indicated that the SL-UCM is reliable for the purpose of climate simulation, but for the evaluation of the UHI intensity and to analyse more sophisticated structures, the multi-layer of the UCM has to be applied in order to account for the turbulence and multi reflection in the urban canopy. It should be noted that running the model with ML-UCM increases the computational time by $30-40 \%$ compared to the time needed for slab model and SL-UCM. Therefore, if the climate prediction is the only purpose of the modelling, the slab model and SL-UCM can provide acceptable results in a shorter time.

\section{Acknowledgement}

Funding for this research was provided by the NSERC DG \#2016-04904 and the Ontario Ministry of Research Innovation and Science (MRIS) through the ERA award.

\section{References}

Akbari, H., Rose, L. S., \& Taha, H. (2003). Analyzing the land cover of an urban environment using highresolution orthophotos. Journal of Landscape and Urban Planning 63, 1-14.

Akbari, H., \& Rose, L. S. (2008). Urban surfaces and heat island mitigation potentials. Journal of the HumanEnvironmental System 11, 85-101.

Akbari, H., Menon, S., \& Rosenfeld, A. (2009). Global cooling: increasing world-wide urban albedos to offset CO2 . Journal of Climatic Change 94, 275-286.

Akbari, H., Matthews, H. D., \& Seto, D. (2012). The Long-Term Effect of Increasing the Albedo of Urban Areas. Environ. Res. Lett. 7, 58-93.

Berardi U. (2016). The outdoor microclimate benefits and energy saving resulting from green roofs retrofits, Energy and Buildings 121, 217-229.

Berardi U., GhaffarianHoseini A., GhaffarianHoseini A. (2014). A critical analysis of the environmental benefits of green roofs, Appl. Energ. 115, 411-428.

Grimmond, C. S., et al. (2010). The International Urban Energy Balance Models Comparison Project: First Results from Phase 1. Journal of Applied Meteorology and Climatology 49, 1260-1292.

Jandaghian Z., Berardi U. 2019a. Analysis of the cooling effects of higher albedo surfaces during heat waves coupling the Weather Research and Forecasting model with building energy models. In Press at Energy and Building.

Jandaghian Z., Berardi U. 2019b. Selection of the Urban Canopy Model for Climate Simulations:A Case Study in the Greater Toronto Area. In Press at Sustainable Cities and Society.

Janjic, Z. (1990). The Step-mountain Coordinate: Physics Package. Mon Weather Rev 118, 1429-1443.

Janjic, Z. (1994). The Step-Mountain Eta Coordinate Model: Further Developements of the Convection, Viscous Sublayer, and Turbulence Closure Schemes. Monthly Weather Review 122, 927-945.

Jandaghian Z., Akbari H. 2019. Effects of increasing surface reflectivity on aerosol, radiation-cloud interactions. In press at Theoretical and Applied Climatology.

Jin, M. S. (2012). Developing an Index to Measure Urban Heat Island Effect Using Satellite Land Skin Temperature and Land Cover Observations. Journal Of Climate 25, 6193-6202. 
Jandaghian, Z., and Akbari, H. (2016). Urban Heat Island and Human Health. $4^{\text {th }}$ International Conference on Countering Urban Heat Island (UHI) and Climate Change Through Mitigation and Adaptation, Singapour, October 2016.

Jandaghian, Z., and Akbari, H. (2017). The Effects of Urban Heat Island on Aerosol-radiation-cloud Interactions in the Atmosphere over North America during Heatwave Period. $6^{\text {th }}$ International Conference on Climate Change, Toronto (ON), Sep 2017.

Janjic, Z. (2002). Nonsingular Implementation of the Mellor-Yamada Level 2.5 Scheme in the NCEP Meso model. Camp Springs, MD. National Centers for Environmental Prediction.

Jandaghian, Z., Touchaei, A.G., Akbari, H. (2017). Sensitivity Analysis of Physical Parameterizations in WRF of Urban Climate Simulations and Heat Island Mitigation in Montreal. Urban Climate 24, 577-599.

Jandaghian, Z., and Akbari, H. (2018a). The effects of increasing surface reflectivity on heat-related mortality in Greater Montreal Area, Canada. Urban Climate 25, 135-151

Jandaghian, Z., and Akbari, H. (2018b). The effects of increasing surface albedo on urban climate and air quality: a detailed study for Sacramento, Houston and Chicago. Journal of Climate 6, 2-19.

Jandaghian, Z., and Akbari, H. (2018c). Effects of Increasing Surface Reflectivity on Urban Climate and Air Quality over North America. $4^{\text {th }}$ International Conference on Building, Energy, Environment, COBEE, Melbourne. Feb 2018.

Jandaghian, Z. (2018). Flow and Pollutant Dispersion Model in a 2D Urban Street Canyons Using Computational Fluid Dynamics. Journal of Computational Engineering and Physical Modeling. Journal of Computational Engineering and Physical Modeling 1, 83-93.
Jandaghian Z, Dorostkar M.M, Wang L. (2018). Flow and pollutant dispersion in urban street canyons: SemiLagrangian approach with zero-equation turbulence model, Building Simulation Conference eSim 2018. Montreal (QC), May 2018.

Kusaka, H., Kondo, H., Kikegawa, Y., Kimura, F. (2001). A simple single-layer urban canopy model for atmospheric models: Comparison with multi-layer and slab models. Bound.-Layer Meteor 101, 329-358.

Kusaka, H., \& Kimura, F. (2004). Coupling a single-layer urban canopy model with a simple atmospheric model: Impact on urban heat island simulation for an idealized case. J. Meteor. Soc. Japan 82, 67-80.

Kusaka, H., Fei, C., Tewari, M., Dudhia, J., Gill, D. O., Duda, M. G., et al. (2012). Numerical Simulation of Urban Heat Island Effect by the WRF Model with 4km Grid Increment: An Inter-Comparison Study between the Urban Canopy Model and Slab Model. Journal of the Meteorological Society of Japan 90, 3345.

Salamanca, F., \& Martilli, A. (2012). A Numerical Study of the Urban Heat Island over Madrid during the DESIREX (2008) Campaign with WRF and an Evaluation of Simple Mitigation Strategies. International Journal of Climatology 15, 2372-2386.

Salamanca, F., Martilli, A., Tewari, M., Chen, F. (2011). A Study of the Urban Boundary Layer Using Different Urban Parameterizations and High-Resolution Urban Canopy Parameters with WRF. Journal of Applied Meteorology and Climatology 50, 1107-1128.

Wang, Y., Berardi, U., Akbari, H. (2016). Comparing the effects of urban heat island effect mitigation strategies $\mathrm{n}$ the city of toronto, Energy and Buildings 114, 2-19. 